\title{
Understanding the Role of Some Demographic Factors and Forgiveness in Shaping the Flourishing of Hindu Married Couples
}

\author{
Priyanka Parihar ${ }^{1}$, Gyanesh Kumar Tiwari ${ }^{1}$, and Pramod Kumar Rai ${ }^{1}$ \\ ${ }^{1}$ Department of Psychology, School of Humanities \& Social Sciences, Doctor Harisingh \\ Gour Vishwavidyalaya, Sagar, 470003, Madhya Pradesh, India
}

May 18, 2020

\begin{abstract}
Hindu Marriage is a sacrament that has been conceived to achieve a variety of worldly and spiritual goals. Some forms of hurt, untruthful or betrayal may involve in a marriage relationship that may significantly impact forgiveness behaviours of one or other member of married couples influencing their flourishing. The study examined the role of some biographic features, the forgiveness of self, others and situations in shaping the well-being of the married Hindu couples. Employing a correlational design, the study recruited 300 married Hindu couples with age ranging from 25 to 50 years by a snowball sampling. Forgiveness and well-being were measured with the help of The Heartland Forgiveness Scale (Thompson et al., 2005) and Mental Health Continuum (Keyes, 2005). The findings showed that education, age, domicile, occupation and years of marriage and the three types of forgiveness exhibited significant positive correlations with the indices of well-being whereas gender, number of children, nature of family (nuclear or joint), number of family members and socioeconomic status showed negative correlations with the same. Employment status and age emerged as the most significant predictors for hedonic and psychological well-being, respectively. Conversely, others forgiveness did the same for social and eudaimonic well-being and flourishing. Indian socio-cultural conditions, the conceptualization of Hindu marriage and relevant earlier studies have been used to discuss the findings. Some biographic attributes, inclination towards postmodern lifestyle and others forgiveness seem to shape the well-being outcomes of the married Hindu couples. Directions of future researchers have been discussed.
\end{abstract}

\section{Keywords}

Forgiveness; hedonic well-being; eudaimonic well-being; human flourishing; Hindu married couples.

\section{Introduction}

Forgiveness has been suggested to play an important role in human relationships of all sorts but its systematic empirical enquiry took a new momentum only after the establishment of Positive Psychology in 2000. Forgiveness involves intra-individual and pro-social change towards a perceived transgression situated in a specific interpersonal context (McCullough, Bellah, Kilpatrick, \& Johnson, 2001). Forgiveness catalyzes positive changes that involve willingness, consent and conscious decision of the forgivers (Worthington et al., 2007). Many benefits of observing and practising forgiveness have been reported by researchers. For example, forgiveness has been observed to be effective in mental and physical health (Harris \& Thoresen, 2005). Maltby, Macaskill and Day (2001) have found that forgiveness is an important psychological construct to understand health and other significant life outcomes. For example, forgiveness has been observed to actuate internal harmony, positive emotions and cognitions, reparative vigour, empathy, well-being, positive health outcomes and useful relationships for both children and adults (Ahirwar et al., 2019; Pandey et al., 2019, 2020). 
Forgiveness has also been argued to be significant for a romantic relationship, marital longevity and satisfaction (Fenell, 1993). Forgiveness carries relevance in the healing of relationship transgressions involving betrayal (Gordon et al., 2005) and relationship hurts (Fincham et al., 2004). Forgiveness is positively associated with psychological well-being because it helps people preserve and reinstate lost relationships (Karremans et al., 2003). According to self-determination theory, forgiveness is linked with well-being as helps to influence the forgiver's perceptions of his or her relationship and connectedness with the transgressor (Reis et al., 2000).

It has been argued that successful marriage depends upon the forgiveness of couples (Worthington \& Scherer, 2004). Forgiveness has been observed to play a facilitative role in facing current problems, avoiding new problems and to uphold the relationships of couples (Worthington \& Scherer, 2004). It has been suggested that forgiveness can regain faith in a marital relationship in the face of contravention (Gordon et al., 2000). It is also important to understand the relationship between marital satisfaction (Fincham \& Linfield, 1997), conflict and negative attributions, lowered loyalty, and non-empathetic attitudes in marital relationships (Fincham et al., 2006). Self-forgiveness helps to give up negative thoughts, feelings and behaviours and helps replace these with positive behaviours towards self (Enright, 1996). Self-forgiveness enables individuals to become aware and deal with their negative feelings. Self-forgiveness is enhances wellbeing by helping people upholding good, useful and compassionate relationships (McCullough, Pargament, \& Thoresen, 2000).

\section{Present Study}

The above discussion makes it clear that forgiveness is a positive strength that helps replace negative cognitions, affects and behavioural outcomes with positive ones. It has been observed that forgiveness helps to reinstate fragmented relationships, lowers resentment and cures emotional injury arising out of worsened marital relationships (Fincham et al., 2002). In spite of the growing research on forgiveness, its role in the marriage relationship is not well-studied (Kearns \& Fincham, 2004; McCullough et al., 1998). Thus, forgiveness carries relevance to underscore well-being and other life outcomes of individuals (Karremans et al., 2003). On the other hand, non-forgiving behaviours have been reported to be positively linked with psychopathological symptoms (Berry \& Worthington, 2001). McCullough et al. (2001) have suggested that self-forgive helps individuals to make the feelings, actions and beliefs about their self more positive that make prompt them to think rationally and act constructively. Thus, self-forgiveness may also have significant relevance in close relationships as the nature of marriage relationships are regulated through attributions, emotional reactions and empathy.

The studies showed that forgiving people have been found to be able to reconstruct wrongdoings in a positive sequence of events about the offenders, offences and their consequences. Furthermore, it has been argued that forgiveness of self and situations may be crucial to understand the relationship between forgiveness of others and positive outcomes in marital relationships (Heinze \& Snyder, 2001). Forgiveness may have a positive impact on marriage as it lowers psychological aggression and enhances constructive communication (Fincham et al., 2004). Forgiveness may carry relevance in marital relationships as it lowers retaliation and enhances benevolence (Fincham et al., 2004). Contrarily, un-forgiveness may carry forward the unsettled transgressions that may escalate future conflicts and negative interaction patterns leading to poor quality of marital relationships (Fincham et al., 2004).

The cultural context of Indian society is dissimilar to that of these societies. Hindu cultural system assumes marriage as one of the sacraments that has worldly as well as eternal aspects. Hindu marriage is assumed to act as a means for people to achieve four Purusharthas of life namely Dharma (religion), Artha (worldly resources), Kama (sensual pleasure) and Moksha (salvation). For example, marriage helps to free an individual from pitri rinas (paternal debt) by giving birth to children. The ultimate goal of Hindu life is to achieve Moksha (salvation). It is the marriage that provides an opportunity for people to attain Moksha by Dharma (religion), Artha (worldly resources) and Kama (sensual pleasure). Thus, Hindu 
marriage is well-structured in its nature, practise and goals that are significantly different from marriage in other religions. Here in India, marriage relationships are generally arranged and are fixed by a set of familial and cultural rules considering genealogy and gotra (lineage). Thus, marriage in India is well-institutionalized and based on a set of philosophical and religious principles. These attributes of Hindu marriage make it a unique system that significantly shapes the relationship of Hindu married couples.

Moreover, socio-cultural realities and traditional practices are facing incessant change in Indian society today. The joint family is being replaced with the nuclear family. Educational and employment opportunities are available to both the sexes. In light of these changes, some characteristic changes in marriage relationship may be expected. Some researchers have argued that Indian society is characterized by both individualism and collectivism (Sinha \& Tripathi, 1994). This observation has recently been verified in a study in India that found self-esteem (suggested to be relevant to understand behaviours and performance of individuals from individualistic societies) and self-compassion (suggested to be useful to understand behaviours and performance of individuals from collectivistic societies) to be relevant for understanding well-being of young adults (Pandey et al., 2019). Thus, it is explicit that there is a lack of research exploring the relationships between three facets of forgiveness (forgiveness of self, others and situations) and various dimensions of the human flourishing of married couples in the changing socio-cultural and demographic contexts. In the background of these arguments, the present study aims to understand the role of some biographical factors and three facets of forgiveness (forgiveness of self, others and situations) in shaping various aspects of the human flourishing of Hindu married couples.

\section{Objectives}

The following objectives have been set for the present study:

1. To understand the nature and degree of association among some biographical features, the forgiveness of self, others and situations and various dimensions of the well-being of married couples, and

2. To assess the relative predictive strengths of some biographical features and three components of forgiveness in accounting for significant change in the various dimensions of the well-being of married couples.

\section{Hypotheses}

Based on the understanding of the available literature on forgiveness and well-being, the following hypotheses were proposed for the present study:

1. Education, age, domicile, occupation and years of marriage positive and the three types of forgiveness will show positive correlations with the various dimensions of the well-being of married couples. Conversely, negative correlations will be observed among gender, number of children, nature of family, number of family members and socioeconomic status of the participants.

2. The biographic variables and the three types of forgiveness will contribute significant variability in the various dimensions of the well-being of married couples.

\section{Methods and Materials}

\section{Sample}

In the present study, a correlational research design was employed that used a snowball sampling technique to select the participants. The data were collected from 300 Hindu married couples with age ranging from 26 years to 50 years of the residents of Sagar city, Madhya Pradesh, India. Most of the 
participants were chosen from the middle-class Hindu families. The biographic details such as education, gender, age, domicile, occupation, length of the marriage, number of children, nature of family and number of family members were recorded with the help of a scale. Socioeconomic status of the participants was measured through a standardized scale (Aggarwal et al., 2005).

\section{Inclusion and Exclusion Criteria}

The participants with at least five years of married with reported normal physical and mental health were allowed to take part in the study. Only Hindu married couples were included in the study. Moreover, the participants whose age ranged between 25 years to 50 years were included in the study. Those couples who belonged to other religious communities, reported some health problems, recent marriage and did not fell under the prescribed age range were excluded from the study.

\section{Tools}

The present study employed the following tools for data collection:

\section{Heartland Forgiveness Scale (HFS)}

The Heartland Forgiveness Scale (Thompson et al., 2005) was utilized for the measurement of forgiveness of self, others and situations. The scale consists of 18 items that provided the participants with the opportunity to express their experiences of forgiveness on a 7-point scale that ranged from "Almost Always False Than True" (1) to "Almost Always True Of Me" (7). This measure of forgiveness comprises three subscales for measuring forgiveness of self, others and situation. The Chronbach Alpha coefficients of reliability for the forgiveness of self, others, situation and for the overall scale were reported to be $0.75,0.78$, 0.77 and 0.86 , respectively (Thompson et al., 2005).

\section{Mental Health Continuum-Short Form}

For measuring hedonic and eudaimonic well-being, The Mental Health Continuum-Short Form (MHC-SF) (Keyes, 2005) was used. The scale has been based on the model of flourishing having theoretical origins from three sources: studies on emotional well-being (Diener et al., 1999), hedonic (subjective or emotional) well-being, psychological well-being (Ryff, 1989) and social well being (Keyes, 1998). This scale consists of 14 items requires from the respondents to rate their experiences over the last month on a 6-point scale ('never', 'once or twice', 'about once a week', '2 or 3 times a week, 'almost every day', or 'every day').

The combined scores of psychological and social well being make eudaimonic well-being. An overall score of the scale is termed as human flourishing. The internal consistency reliability is over 0.80 (Keyes, 2005).

\section{Procedure}

After planning the study, the proposal was submitted to the Ethics committee of a University [BLINDED], India for ethical approval. Then the prospective couples were contacted personally by the first author who debriefed them about the basic objective of the study and asked for their voluntary participation and written consent. All the questionnaires were originally available in English that were translated in Hindi by adopting a translation-back-translation method. All relevant demographic details like age, sex, residence and education etc. were taken from the participants. The questionnaires were administered in personal visits by the first author.

\section{Data Analysis Plan}

The completed questionnaires were scored and the raw scores were arranged as per the need for statistical analysis. The mean scores, standard deviations (SDs), coefficient of correlation and hierarchical 
regression analysis were calculated through SPSS 25v available in the University.

\section{Results}

The results of the study have been described in two sections: 1) Correlation Analysis, and 2) Hierarchical Regression Analysis.

\section{Correlation Analysis}

Table 1 shows that education demonstrated significant positive correlations with the scores of Domicile, Occupation, Years of Marriage, Number of Children, Nature of Family, Socioeconomic Status, Self-Forgiveness, Interpersonal Forgiveness, Situational Forgiveness, Heartland Forgiveness Scale, Emotional Well-being, Social Well-being, Psychological Well-being, Eudaimonic Well-being and Human Flourishing of the participants. Gender showed significant positive correlations with the scores of age, occupation, number of children and socioeconomic status of the participants. Age showed significant positive correlations with the scores of gender, occupation, years of marriage number of children, number of family members, Interpersonal Forgiveness, Situational Forgiveness, Heartland Forgiveness Scale, Emotional Well-being, Psychological Well-being, Eudaimonic Well-being and Human Flourishing of the participants. Domicile showed significant positive correlations with the scores of Education, Socioeconomic Status, Self-Forgiveness, Interpersonal Forgiveness, Situational Forgiveness, Heartland Forgiveness Scale, Psychological Well-being, Eudaimonic Well-being and Human Flourishing of the participants. Occupation showed significant positive correlations with the scores of Education, Gender, Age, Number of Children, Socioeconomic Status, Emotional Wellbeing, Social Well-being, Psychological Well-being, Eudaimonic Well-being and Human Flourishing of the participants. Years of Marriage showed significant positive correlations with the scores of Education, Age, Number of Children, Nature of Family, Interpersonal Forgiveness, Situational Forgiveness, Heartland Forgiveness Scale, Emotional Well-being, Psychological Well-being, and Human Flourishing of the participants (see Table 1).

Table 1. Coefficients of correlations among demographic attributes, Forgiveness and well-being of the participants ( $\mathrm{N}=300$ married couples)

\begin{tabular}{|c|c|c|c|c|c|c|c|c|c|c|c|}
\hline S. No. & Measures & Mean (SD) & 1 & 2 & 3 & 4 & 5 & 6 & 7 & 8 & 9 \\
\hline 1 & EDU & $1.70(0.46)$ & 1 & & & & & & & & \\
\hline 2 & Gender & $1.50(0.50)$ & -.073 & 1 & & & & & & & \\
\hline 3 & Age & $38.42(7.89)$ & .004 & $-.211^{* *}$ & 1 & & & & & & \\
\hline 4 & DOM & $1.83(0.38)$ & $.256^{* *}$ & -.013 & .073 & 1 & & & & & \\
\hline 5 & $\mathrm{ES}$ & $1.60(0.49)$ & $.170^{* *}$ & $-.680^{* *}$ & $.174^{* *}$ & .034 & 1 & & & & \\
\hline 6 & LOML & $15.19(7.80)$ & $-.121^{* *}$ & -.013 & $.824^{* *}$ & .050 & .034 & 1 & & & \\
\hline 7 & $\mathrm{NOC}$ & $1.47(0.79)$ & $-.090^{*}$ & $.093^{*}$ & $.500^{* *}$ & -.071 & $-.083^{*}$ & $.476^{* *}$ & 1 & & \\
\hline 8 & $\mathrm{NOF}$ & $1.64(0.48)$ & $-.117^{* *}$ & .010 & $-.108^{* *}$ & -.048 & -.013 & $-.080^{*}$ & $-.248^{* *}$ & 1 & \\
\hline 9 & NOFM & $6.53(4.60)$ & .017 & .002 & .068 & .046 & -.018 & .066 & -.017 & $.447^{* *}$ & 1 \\
\hline 10 & SES & $56.26(12.47)$ & $.253^{* *}$ & $-.107^{* *}$ & -.006 & $.150^{* *}$ & $.102^{*}$ & -.070 & $-.097^{*}$ & .010 & .071 \\
\hline 11 & $\mathrm{SF}$ & $25.60(3.68)$ & $.169^{* *}$ & -.015 & .056 & $.092^{*}$ & .047 & .018 & -.044 & -.024 & .022 \\
\hline 12 & $\mathrm{OF}$ & $26.34(4.95)$ & $.111^{* *}$ & .040 & $.149^{* *}$ & .070 & .027 & $.195^{* *}$ & .029 & -.054 & -.002 \\
\hline 13 & $\mathrm{SIF}$ & $25.27(3.57)$ & $.090^{*}$ & -.051 & $.150^{* *}$ & $.100^{*}$ & .050 & $.088^{*}$ & -.001 & -.038 & .063 \\
\hline 14 & $\mathrm{OVF}$ & $127.91(15.09)$ & $.133^{* *}$ & .022 & $.119^{* *}$ & $.121^{* *}$ & .005 & $.113^{* *}$ & -.031 & -.043 & .031 \\
\hline 15 & EWB & $10.97(3.56)$ & $.085^{*}$ & -.073 & $.226^{* *}$ & $.171^{* *}$ & $.145^{* *}$ & $.194^{* *}$ & $.110^{* *}$ & $-.091^{*}$ & .007 \\
\hline 16 & SWB & $14.66(5.55)$ & $.185^{* *}$ & -.023 & .043 & .006 & $.104^{*}$ & -.041 & -.008 & $-.111^{* *}$ & $-.123^{* *}$ \\
\hline 17 & PWB & $21.55(5.73)$ & $.193^{* *}$ & -.047 & $.227^{* *}$ & $.169^{* *}$ & $.136^{* *}$ & $.164^{* *}$ & .067 & $-.161^{* *}$ & $-.103^{*}$ \\
\hline
\end{tabular}




\section{Note 1}

$\mathbf{D O M}=$ Domicile, $\mathbf{E D U}=$ Education, $\mathbf{E D W B}=$ Eudaimonic Well-being, EWB $=$ Emotional Well-being, $\mathbf{H F}=$ Human Flourishing, $\mathbf{N O C}=$ Number of Children, NOF $=$ Nature of Family, NOFM = Number of Family Members, $\mathbf{O F}=$ Others Forgiveness, $\mathbf{O S}=$ Employment Status, $\mathbf{O V F}=$ Overall Forgiveness, $\mathbf{P W B}=$ Psychological Well-being, SES = Socioeconomic Status, $\mathbf{S F}=$ Self-Forgiveness, $\mathbf{S I F}=$ Situational Forgiveness, $\mathbf{S W B}=$ Social Well-being, $\mathbf{L O M L}=$ Length of married life.

\section{Note 2}

*. Correlation is significant at the 0.05 level, ${ }^{* *}$. Correlation is significant at the 0.01 level

Number of Children showed significant positive correlations with the scores of Education, Gender, Age, Occupation, Years of Marriage, Nature of Family, Socioeconomic Status and Emotional Well-being of the participants. Nature of Family showed significant positive correlations with the scores of Education, Age, Years of Marriage, Number of Children, Number of Family Members, Emotional Well-being, Social Wellbeing, Psychological Well-being, Eudaimonic Well-being and Human Flourishing of the participants. The Number of Family Members showed significant positive correlations with the scores of Nature of Family, Social Well-being, Psychological Well-being, Eudaimonic Well-being and Human Flourishing of the participants. Socioeconomic Status showed significant positive correlations with the scores of Nature of Family, Social Well-being, Psychological Well-being, Eudaimonic Well-being and Human Flourishing of the participants. Self-Forgiveness showed significant positive correlations with the scores of Education, Domicile, Interpersonal Forgiveness, Situational Forgiveness, Heartland Forgiveness Scale, Emotional Well-being, Social Well-being, Psychological Well-being, Eudaimonic Well-being and Human Flourishing of the participants. Interpersonal Forgiveness showed significant positive correlations with the scores of Education, Age, Years of Marriage, Socioeconomic Status, Self-Forgiveness, Situational Forgiveness, Heartland Forgiveness Scale, Emotional Well-being, Social Well-being, Psychological Well-being, Eudaimonic Well-being and Human Flourishing of the participants (see Table 1).

Situational Forgiveness showed significant positive correlations with the scores of Education, Age, Years of Marriage, Socioeconomic Status, Self-Forgiveness, Heartland Forgiveness Scale, Emotional Well-being, Social Well-being, Psychological Well-being, Eudaimonic Well-being and Human Flourishing of the participants. Heartland Forgiveness Scale showed significant positive correlations with the scores of Education, Age, Domicile, Years of Marriage, Socioeconomic Status, Self-Forgiveness, Interpersonal Forgiveness, Situational Forgiveness, Emotional Well-being, Social Well-being, Psychological Well-being, Eudaimonic Well-being and Human Flourishing of the participants. Emotional Well-being showed significant positive correlations with the scores of Education, Age, Domicile, Occupation, Years of Marriage, Number of Children, Nature of Family, Self-Forgiveness, Interpersonal Forgiveness, Situational Forgiveness, Heartland Forgiveness Scale, Social Well-being, Psychological Well-being, Eudaimonic Well-being and Human Flourishing of the participants. Social Well-being showed significant positive correlations with the scores of Education, Occupation, Nature of Family, Number of Family Members, Self-Forgiveness, Interpersonal Forgiveness, Situational Forgiveness, Heartland Forgiveness Scale, Emotional Well-being, Psychological Well-being, Eudaimonic Well-being and Human Flourishing of the participants. Psychological Well-being showed significant positive correlations with the scores of Education, Age, Domicile, Occupation, Years of Marriage, Nature of Family, Number of Family Members, Self-Forgiveness, Interpersonal Forgiveness, Situational Forgiveness, Heartland Forgiveness Scale, Emotional Well-being, Social Well-being, Eudaimonic Well-being and Human Flourishing of the participants. Eudaimonic Well-being showed significant positive correlations with the scores of Education, 
Age, Domicile, Occupation, Nature of Family, Number of Family Members, Self-Forgiveness, Interpersonal Forgiveness, Situational Forgiveness, Heartland Forgiveness Scale, Emotional Well-being, Social Well-being, Psychological Well-being, and Human Flourishing of the participants. Human Flourishing showed significant positive correlations with the scores of Education, Age, Domicile, Occupation, Years of Marriage, Nature of Family, Number of Family Members, Self-Forgiveness, Interpersonal Forgiveness, Situational Forgiveness, Heartland Forgiveness Scale, Emotional Well-being, Social Well-being, Psychological Well-being and Eudaimonic Well-being of the participants (see Table 1).

\section{Hierarchical Regression Analysis}

The demographic variables (Education, Gender, Age, Domicile, Occupation, Years of Marriage Number of Children Nature of Family Number of Family Members and Socioeconomic Status,) were entered at step 1 followed by Self-Forgiveness, Interpersonal Forgiveness, Situational Forgiveness, Heartland Forgiveness Scale which were entered at step 2 in a stepwise fashion (see Table 2).

The results showed that demographic variables (Education, Gender, Age, Domicile, Occupation, Years of Marriage Number of Children Nature of Family Number of Family Members and Socioeconomic Status) accounted for significant variance by contributing $9.8 \%$ in the scores of Hedonic Well-being $\left(\mathrm{R}^{2}=.098, \mathrm{~F}\right.$ $(10,589)=6.367, p=.001)$. Likewise, Education, Gender, Age, Domicile, Occupation, Years of Marriage Number of Children Nature of Family Number of Family Members and Socioeconomic Status exhibited their cumulative contributions of $7.5 \%, 14.6 \%, 12.4 \%$ and $12.6 \%$ in Social Well-Being $\left(\mathrm{R}^{2}=.075, \mathrm{~F}(10,589)\right.$ $=4.745, p=.001)$, Psychological Well-Being $\left(\mathrm{R}^{2}=.146, \mathrm{~F}(10,589)=10.109, p=.001\right)$, Eudaimonic Well-Being $\left(\mathrm{R}^{2}=.124, \mathrm{~F}(10,589)=8.346, p=.001\right)$ and Human Flourishing $\left(\mathrm{R}^{2}=.126, \mathrm{~F}(10,589)=\right.$ $8.455, p=.001$ ) as has been depicted in model 1 of each component of human flourishing, respectively (see Table 2).

Table 2. Results of Hierarchical Regression analyses using demographic attributes and forgiveness as predictor variables and five dimensions of well-being as outcome variables $(\mathrm{N}=$ 300 married couples)

\begin{tabular}{llllll}
\hline & HWB & SWB & PWB & EDWB & HF \\
Predictors & Model 1 & Model 2 & Model 1 & Model 2 & Model 1 \\
Education & .038 & .009 & $.162^{* *}$ & $.140^{* *}$ & $.160^{* *}$ \\
Gender & .061 & .050 & $.116^{*}$ & .106 & $.109^{*}$ \\
Age & .141 & .112 & $.222^{* *}$ & $.211^{* *}$ & $.260^{* *}$ \\
Domicile & $.149^{* *}$ & $.138^{* *}$ & -.040 & -.046 & $.120^{* *}$ \\
Occupation & $.155^{* *}$ & $.148^{* *}$ & $.123^{*}$ & $.116^{*}$ & $.139^{* *}$ \\
Years of Marriage & .053 & .040 & $-.187^{* *}$ & $-.210^{* *}$ & -.020 \\
Number of Children & .015 & .037 & -.036 & -.021 & -.065 \\
Nature of Family & -.064 & -.053 & -.048 & -.041 & $-.090^{*}$ \\
Nature of Family Members & .022 & .013 & $-.101^{*}$ & $-.105^{*}$ & -.077 \\
Socioeconomic Status & -.055 & -.032 & -.039 & -.020 & $-.124^{*}$ \\
SF & & .066 & & .023 & \\
IF & & $.088^{*}$ & & $.105^{*}$ & \\
SIF & & $.085^{*}$ & & .036 & \\
$\mathbf{R}^{2}$ & .098 & .124 & .075 & .090 & .146 \\
{$[?] \mathbf{R}^{2}$} & .098 & .026 & .075 & .015 & .146 \\
[?]F & $6.367^{* *}$ & $5.867^{* *}$ & $4.745^{* *}$ & $3.216^{*}$ & $10.109^{* *}$ \\
\hline
\end{tabular}

Note 1. All standardized regression coefficients $(\beta)$ belong to final step of the analyses. df Model $1=(10$, 
589) and Model $2=(3,586)$

Note 2. $\mathbf{E D W B}=$ Eudaimonic Well-being, $\mathbf{E W B}=$ Emotional Well-being, $\mathbf{S F}=$ Self-Forgiveness, $\mathbf{H F}$ $=$ Human Flourishing. $\mathbf{I F}=$ Interpersonal Forgiveness, $\mathbf{O F}=$ Overall Forgiveness, $\mathbf{P W B}=$ Psychological Well-being, SES $=$ Socioeconomic Status, $\mathbf{S I F}=$ Situational Forgiveness, $\mathbf{S W B}=$ Social Well-being.

Note 3. *. Correlation is significant at the 0.05 level, **. Correlation is significant at the 0.01 level.

The results also demonstrated that Forgiveness of Self, Forgiveness of Others, Forgiveness of Situation, Overall Forgiveness contributing 12.4\%, 10.1\%, 20.6\%, 17.5\%, and 17.6\% in Hedonic Well-Being $\left(\mathrm{R}^{2}=.124, \mathrm{~F}(3,586)=5.867, p=.001\right)$, Social Well-Being $\left(\mathrm{R}^{2}=.101, \mathrm{~F}(3,586)=3.216, p=.001\right)$, Psychological Well-Being $\left(\mathrm{R}^{2}=206, \mathrm{~F}(3,586)=13.935, p=.001\right)$, Eudaimonic Well-Being $\left(\mathrm{R}^{2}=.175, \mathrm{~F}\right.$ $(3,586)=9.970, p=.001)$ and Human Flourishing $\left(\mathrm{R}^{2}=.176, \mathrm{~F}(3,586)=10.447, p=.001\right)$ as has been depicted in model, respectively (see Table 2).

It is also evident that the addition of Forgiveness of Self, Forgiveness of Others, Forgiveness of Situation, Overall Forgiveness at step 2 for Hedonic Well-being caused .026 unit significant change in Hedonic Well-being. For Social Well-being, the addition of Forgiveness of Self, Forgiveness of Others, Forgiveness of Situation, and Overall Forgiveness at step 2 accounted for .015 unit significant change in Social WellBeing. Likewise, the addition of Forgiveness of Self, Forgiveness of Others, Forgiveness of Situation, Overall Forgiveness at step 2 caused .057 unit significant change in Psychological Well-Being. Moreover, the addition of Forgiveness of Self, Forgiveness of Others, Forgiveness of Situation, Heartland Forgiveness Scale at step 2 caused .043 unit significant change in Eudaimonic Well-Being. The addition of Forgiveness of Self, Forgiveness of Others, Forgiveness of Situation, Heartland Forgiveness Scale at step 2 caused .044 unit significant change in Human Flourishing (see Table 3).

\section{Discussion}

The findings showed that education, age, domicile, occupation and years of marriage and the three types of forgiveness exhibited positive correlations with well-being whereas negative correlations were recorded among gender, number of children, nature of family (nuclear or joint), number of family members and socioeconomic status and well-being measures of the participants. Employment status and age emerged as the most significant factors to account for significant change in hedonic and psychological well-being, respectively. Conversely, the others forgiveness did the same for social and eudaimonic well-being and human flourishing.

Various biographic attributes exhibited dissimilar predictive strengths to different indices of well-being in Model 1. For example, education, gender and age exhibited their positive significant predictive potentials for social, psychological and eudaimonic well-being and flourishing. Similarly, domicile signified its positive predictive strength for hedonic and psychological well-being. Employment status showed its positive significant predictive strengths for all dimension of well-being measure while the length of married life negatively shaped social and eudaimonic well-being. The nature of family (nuclear or joint) negatively predicted psychological well-being of married Hindu couples. The number of family members negatively predicted social, psychological and eudaimonic well-being. The socioeconomic status of the couples also negatively predicted psychological, eudaimonic well-being and flourishing measures. The biographic attributes $1.50 \%$ to $14.60 \%$ changes in the scores of the various indices of well-being.

In model 2, the role of forgiveness of self, others and situations were explicit. Self-forgiveness predicted positively social and eudaimonic well-being, and flourishing measures while others forgiveness had positive predictive value for social, psychological and eudaimonic well-being, and flourishing dimensions. Forgiveness of situations signified positive predictive strength for all the indices of well-being. It was evident that others forgiveness carried the highest predictive strength for the eudaimonic measure while forgiveness of situations was most relevant for hedonic one. The additions of the three types of forgiveness at step 2 caused significant 
change ranging from $2.70 \%$ to $14.60 \%$ variability in hedonic, social, psychological and eudaimonic well-being, and flourishing measures, respectively. The predictive role of forgiveness may be understood in terms of the meaning inherent in the conceptualization of well-being in the measure. The hedonic well-being reflected happiness, interest in life, enjoyment from various sources and satisfaction with life that may be argued to be more close to forgiveness of situations. This might have happened due to the fact that forgiveness of situations reflected rational and positive thinking, perseverance, tolerance, adaptability, easy acceptance of situations and higher control of negative thoughts. Similarly, eudaimonic well-being comprised of social and psychological well-being. Social well-being signified social contribution of individual, integration with social realities and dynamics, actualization social goals, acceptance by others, coherence or interest in social events while psychological well-being reflected self-acceptance, environmental mastery, useful relations with others, personal growth, autonomy and purpose in life (Keyes, 2005; Lupano Perugini et al., 2017; Pandey et al., 2020). Forgiveness of self may have exerted its impacts on eudaimonic well-being as it signified selfreparation, self-criticism, self-promotion, self-acceptance and accumulation of relevant experiences. Likewise, the forgiveness of other shaped eudaimonic well-being more efficiently as it denoted non-punitive, realistic understanding of others, non-retaliation, acceptance, unconditional and positive behaviours towards others (Thompson et al., 2005).

Education provides individuals with an opportunity to widen their cognitive, affective and behavioural horizons and enhances the feeling of self-worth, efficacy, self-esteem and general understanding. These attributes of education might be behind its positive correlations and predictive strengths for social and psychological well-being. Indian society is still known for its traditional practices and cultural values. Here in Indian society, being male makes assured availability of social and psychological resources. For example, men are still assumed as more skilled, entrepreneur, worthy, and suitable for most of the jobs. These differential conceptualizations of gender in Indian society may have their dissimilar experiences of eudaimonic well-being. Rural and urban areas are characterized by dissimilar availability of educational and employment opportunities, autonomy, future prospects and quality of life. These attributes of urban domicile may have linked it positively with hedonic and psychological well-being. Employment status determines the availability of resources accompanied by social prestige, power, decision making and positive identity and these, in turn, may have close connections with hedonic and eudaimonic well-being.

Length of married life and the nature of family (nuclear or joint) had shown negative roles in social and psychological well-being. This may due to the fact that middle adulthood is generally characterized by the demands from all sides of life, increased health issues of self and parents, the stress in work life, promotion etc. These factors may have acted as obstacles before the well-being of the participants. The socioeconomic status (SES) of married couples has shown a negative link with their well-being. This may be due to the fact that a higher SES is coupled with more involvement in business or serving organizations, less time for leisure, family and society and competition in work life. These factors may hinder social contribution, social coherence, social interest, positive relations with others, personal growth, autonomy and purpose in life as conceptualized in mental health continuum measure (Keyes, 2005; Lupano Perugini et al., 2017; Pandey et al., 2020).

Forgiveness of self, others and situations have shown significant positive links with all indices of well-being and slightly dissimilar predictive strengths for various well-being indices in the present study. Self-forgiveness facilitates positive self-understanding, positive frame of mind, effective attributions and positive emotionality that, in turn, may be assumed to be closely linked with social and psychological well-being. These findings have been mirrored in some earlier studies that have shown its positive links with a variety of indices of well-being (Pandey et al., 2020). Likewise, the forgiveness of others enhances positive understanding of other people, interpersonal and social situations. These strengths of forgiveness of others might be working behind its positive and predictive links with social and psychological well-being. Similar findings have also been reported by some earlier studies. Forgiveness of situations involved realistic and positive thinking of transgressing situations, better adaptability and enhanced self-understanding that might be the major reasons behind its close and predictive associations with all indices of well-being used in the present study. Indian marriage system is a sacrament that is well-structured and aims to fulfil not only 
worldly goals but it also acts as the means to achieve religious, social and spiritual goals of life. Through marriage one is inducted into Grahastha Ashram (householder) that helps to satisfy all worldly needs of individuals and also supports other humans and non-humans. It also helps to achieve Dharma (religion), Artha (worldly resources) and Kama (sensual pleasure), the three Purusharthas (desirable) of life. These finally lead one towards the ultimate goal of human life known as Moksha (salvation). This intricate nature of Hindu marriage may also complicate the associated psychological constructs like forgiveness and well-being.

The findings of the study evinced the significane of demographic factors and forgiveness to unerstand the well-being of married couples. There is much to contribute to the study of forgiveness in association with various aspects of life. Future researchers may contribute to this field by carrying out further studies involving other positive psychological constructs such as spirituality, positive body image, interdependent happiness and compassion. The use of qualitative and mixed methods may constitute another way to contribute to this emerging field. Cross-cultural verifications and establishing similarities and differences with these findings may be a novel addition to this area.

\section{References}

Aggarwal, O. P., Bhasin, S. K., Sharma, A. K., Chhabra, P., Aggarwal, K., \& Rajoura, O. P. (2005). A New Instrument (Scale) for Measuring the Socioeconomic Status of a Family: Preliminary Study. Indian Journal of Community Medicine, 30(4), 4.

Ahirwar, G., Tiwari, G. K., \& Rai, P. K. (2019). Exploring the nature, attributes and consequences of forgiveness in children: A qualitative study. Psychological Thought, 12(2), 214-231. https://doi.org/10.5964/psyct.v12i2.347

Berry, J. W., \& Worthington, E. L., Jr. (2001). Forgivingness, relationship quality, stress while imagining relationship events, and physical and mental health. Journal of Counseling Psychology, 48(4), 447-455. https://doi.org/10.1037/0022-0167.48.4.447

Diener, E., Suh, E. M., Lucas, R. E., \& Smith, H. L. (1999). Subjective well-being: Three decades of progress. Psychological Bulletin, 125(2), 276-302. https://doi.org/10.1037/0033-2909.125.2.276

Enright, R. D. (1996). Counseling Within the Forgiveness Triad: On Forgiving, Receiving Forgiveness, and Self-Forgiveness. Counseling and Values, 40(2), 107-126. https://doi.org/10.1002/j.2161007X.1996.tb00844.x

Fenell, D. L. (1993). Characteristics of Long-Term First Marriages. Journal of Mental Health Counseling, $15(4), 446-460$.

Fincham, F. D., Beach, S. R. H., \& Davila, J. (2004). Forgiveness and Conflict Resolution in Marriage. Journal of Family Psychology, 18(1), 72-81. https://doi.org/10.1037/0893-3200.18.1.72

Fincham, F. D., Hall, J., \& Beach, S. R. H. (2006). Forgiveness in Marriage: Current Status and Future Directions. Family Relations, 55(4), 415-427. https://doi.org/10.1111/j.1741-3729.2005.callf.x-i1

Fincham, F. D., \& Linfield, K. J. (1997). A new look at marital quality: Can spouses feel positive and negative about their marriage? Journal of Family Psychology, 11(4), 489-502. https://doi.org/10.1037/08933200.11.4.489-502

Fincham, F. D., Paleari, F. G., \& Regalia, C. (2002). Forgiveness in marriage: The role of relationship quality, attributions, and empathy. Personal Relationships, 9(1), 27-37. https://doi.org/10.1111/1475-6811.00002

Gordon, K. C., Baucom, D. H., \& Snyder, D. K. (2000). The use of forgiveness in marital therapy. In M. E. McCullough, K. Pargament, \& C. Thoresen, (Eds.),Frontiers of Forgiving (pp. 203-227). Guilford Press. 
Gordon, K. C., Baucom, D. H., \& Snyder, D. K. (2005). Treating couples recovering from infidelity: An integrative approach. Journal of Clinical Psychology, 61 (11), 1393-1405. https://doi.org/10.1002/jclp.20189

Harris, A. H. S., \& Thoresen, C. E. (2005). Forgiveness, unforgiveness, health, and disease. In E. L. Worthington Jr. (Ed.),Handbook of for-giveness (pp. 321-334). Routledge.

Heinze, L., \& Snyder, C. R. (2001, August). Forgiveness components as mediators of hostility and PTSD in child abuse.

Karremans, J. C., Van Lange, P. A. M., Ouwerkerk, J. W., \& Kluwer, E. S. (2003). When forgiving enhances psychological well-being: The role of interpersonal commitment. Journal of Personality and Social Psychology, 84(5), 1011-1026. https://doi.org/10.1037/0022-3514.84.5.1011

Kearns, J. N., \& Fincham, F. D. (2004). A Prototype Analysis of Forgiveness. Personality and Social Psychology Bulletin, 30(7), 838-855. https://doi.org/10.1177/0146167204264237

Keyes, Corey L. M. (2005). Mental Illness and/or Mental Health? Investigating Axioms of the Complete State Model of Health. Journal of Consulting and Clinical Psychology, 73(3), 539-548. https://doi.org/10.1037/0022-006X.73.3.539

Keyes, Corey Lee M. (1998). Social Well-Being. Social Psychology Quarterly, 61(2), 121. https://doi.org/10.2307/2787065

Lupano Perugini, M. L., de la Iglesia, G., Castro Solano, A., \& Keyes, C. L. M. (2017). The Mental Health Continuum-Short Form (MHC-SF) in the Argentinean context: Confirmatory factor analysis and measurement invariance. Europe's Journal of Psychology, 13(1), 93-108. https://doi.org/10.5964/ejop.v13i1.1163

Maltby, J., Macaskill, A., \& Day, L. (2001). Failure to forgive self and others: A replication and extension of the relationship between forgiveness, personality, social desirability and general health. Personality and Individual Differences, 30(5), 881-885. https://doi.org/10.1016/S0191-8869(00)00080-5

McCullough, M. E., Pargament, K. I., \& Thoresen, C. E. (2000). The psychology of forgiveness: History, conceptual issues, and overview. In M.E. McCullough, K.I. Pargament, \& C.E. Thoresen (Eds.), Forgiveness: Theory, research, and practice (pp. 1-16). The Guilford Press.

McCullough, Michael E., Bellah, C. G., Kilpatrick, S. D., \& Johnson, J. L. (2001). Vengefulness: Relationships with Forgiveness, Rumination, Well-Being, and the Big Five. Personality and Social Psychology Bulletin, 27(5), 601-610. https://doi.org/10.1177/0146167201275008

McCullough, Michael E., Rachal, K. C., Sandage, S. J., Worthington, E. L., Brown, S. W., \& Hight, T. L. (1998). Interpersonal forgiving in close relationships: II. Theoretical elaboration and measurement. Journal of Personality and Social Psychology, 75 (6), 1586-1603. https://doi.org/10.1037/0022-3514.75.6.1586

Pandey, R., Tiwari, G. K., Parihar, P., \& Rai, P. K. (2019). Positive, not negative, self-compassion mediates the relationship between self-esteem and well-being. Psychology and Psychotherapy: Theory, Research and Practice, papt.12259. https://doi.org/10.1111/papt.12259

Pandey, R., Tiwari, G. K., Parihar, P., \& Rai, P. K. (2020). The relationship between self-forgiveness and human flourishing: Inferring the underlying psychological mechanisms. Polish Psychological Bulletin, 51(1), 29-42. https://doi.org/10.24425/ppb.2020.132649

Reis, H. T., Sheldon, K. M., Gable, S. L., Roscoe, J., \& Ryan, R. M. (2000). Daily Well-Being: The Role of Autonomy, Competence, and Relatedness. Personality and Social Psychology Bulletin, 26(4), 419-435. https://doi.org/10.1177/0146167200266002

Ryff, C. D. (1989). Happiness is everything, or is it? Explorations on the meaning of psychological wellbeing. Journal of Personality and Social Psychology, 57(6), 1069-1081. https://doi.org/10.1037/00223514.57.6.1069 
Sinha, D., \& Tripathi, R. C. (1994). Individualism in a collectivist culture: A case of coexistence of opposites. In U. Kim, H. C. Triandis, C. Kâğitçibaşi, S. C. Choi, \& G. Yoon (Eds.), Cross-cultural research and methodology series, Vol. 18. Individualism and collectivism: Theory, method, and applications (pp. 123136). Sage Publications.

Thompson, L. Y., Snyder, C. R., Hoffman, L., Michael, S. T., Rasmussen, H. N., Billings, L. S., Heinze, L., Neufeld, J. E., Shorey, H. S., \& Roberts, J. C. (2005). Dispositional Forgiveness of Self, Others, and Situations. JOURNAL OF PERSONALITY, 73(2), 313-360.

Worthington, E. L., \& Scherer, M. (2004). Forgiveness is an emotion-focused coping strategy that can reduce health risks and promote health resilience: Theory, review, and hypotheses. Psychology 85 Health, 19(3), 385-405. https://doi.org/10.1080/0887044042000196674

Worthington, E. L., Witvliet, C. V. O., Pietrini, P., \& Miller, A. J. (2007). Forgiveness, Health, and WellBeing: A Review of Evidence for Emotional Versus Decisional Forgiveness, Dispositional Forgivingness, and Reduced Unforgiveness. Journal of Behavioral Medicine, 30(4), 291-302. https://doi.org/10.1007/s10865007-9105-8 